\title{
A violência escolar e a crise da autoridade docente
}

\author{
Júlio Groppa Aquino*
}

\begin{abstract}
RESUMO: O presente artigo discute a relação entre os conceitos de violência e autoridade no contexto escolar e, particularmente, na relação professor-aluno. Para tanto, contrapõe uma leitura de cunho institucional da violência escolar às abordagens clássicas da temática, demonstrando a tese de que há um quantum de violência "produtiva" embutido na ação pedagógica.
\end{abstract}

Palavras-chave: violência escolar, relação professor-aluno, autoridade docente, instituição escola

Várias são as possibilidades de análise ou reflexão que se descortinam quando alguém depara, quer empírica quer teoricamente, com a indigesta justaposição escola/violência, principalmente a partir de seus efeitos concretos: a indisciplina nossa de cada dia, a turbulência ou apatia nas relações, os confrontos velados, as ameaças de diferentes tipos, os muros, as grades, a depredação, a exclusão enfim. O quadro nos é razoavelmente conhecido, e certamente não precisamos de outros dados para melhor configurá-lo.

A imagem, entre nós já quase idílica, da escola como locus de fomentação do pensamento humano - por meio da recriação do legado cultural - parece ter sido substituída, grande parte das vezes, pela visão

* Mestre e doutor em Psicologia Escolar pelo Instituto de Psicologia da USP, e docente na Faculdade de Educação da USP, área de Psicologia da Educação. Autor de Confrontos na sala de aula: Uma leitura institucional da relação professor-aluno (1996), e organizador/co-autor das coletâneas Indisciplina na escola (1996), Sexualidade na escola (1997), Erro e fracasso na escola (1997), Diferenças e preconceito na escola (1998), editadas pela Summus. 
difusa de um campo de pequenas batalhas civis; pequenas mas visíveis o suficiente para causar uma espécie de mal-estar coletivo nos educadores brasileiros. Como se posicionar perante tal estado de coisas?

No meio educacional, duas parecem ser as tônicas fundantes que estruturam o raciocínio daqueles que se dispõem a problematizar os efeitos de violência simbólica ou concreta verificados no cotidiano escolar contemporâneo: uma de cunho nitidamente sociologizante, e outra de matiz mais clínico-psicologizante.

No primeiro caso, tratar-se-ia de perseguir as conseqüências, geralmente conotadas como perversas, das determinações macroestruturais sobre o âmbito escolar, resultando em reações violentas por parte da clientela. No segundo, de pontificar um diagnóstico de caráter evolutivo, quando não patológico, de "quadros" ou mesmo "personalidades" violentas, influenciando a convivência entre os pares escolares. Em ambos os casos, a violência portaria uma raiz essencialmente exógena em relação à prática institucional escolar: de acordo com a perspectiva sociologizante, nas coordenadas políticas, econômicas e culturais ditadas pelos tempos históricos atuais; já na perspectiva clínico-psicologizante, na estruturação psíquica prévia dos personagens envolvidos em determinado evento conflitivo. Vale lembrar que uma combinação de tais perspectivas também pode surgir como alternativa à compreensão de determinada situação escolar de caráter conflitivo, por exemplo, num diagnóstico sociologizante das causas acompanhado de um prognóstico psicologizante em torno de determinados "casos-problema" - o que, inclusive, acaba ocorrendo com certa freqüência no dia-a-dia escolar.

Em termos especificamente institucionais, a ação escolar seria marcada por uma espécie de "reprodução" difusa de efeitos oriundos de outros contextos institucionais molares (a política, a economia, a família, a mídia etc.), que se fariam refletir no interior das relações escolares. De um modo ou de outro, contudo, a escola e seus atores constitutivos, principalmente o professor, parecem tornar-se reféns de sobredeterminações que em muito Ihes ultrapassam, restando-Ihes apenas um misto de resignação, desconforto e, inevitavelmente, desincumbência perante os efeitos de violência no cotidiano prático, posto que a gênese do fenômeno e, por extensão, seu manejo teórico-metodológico residiriam fora, ou para além, dos muros escolares.

Nessa perspectiva, a palavra de ordem passa a ser o "encaminhamento". Encaminha-se para o coordenador, para o diretor, para os pais ou 
responsáveis, para o psicólogo, para o policial. Numa situação-limite, isto é, na impossibilidade do encaminhamento, a decisão, não raras vezes, é o expurgo ou a exclusão velada sob a forma das "transferências" ou mesmo do "convite" à auto-retirada.

Como se pode notar, os educadores quase sempre acabam padecendo de uma espécie de sentimento de "mãos atadas" quando confrontados com situações atípicas em relação ao plácido ideário pedagógico. Entretanto, o cotidiano escolar é pródigo em eventos alheios a esse ideário-padrão. E os efeitos da violência representam, sem dúvida, a parcela mais onerosa de tais vicissitudes.

O que fazer? A partir de tais efeitos, como alçar um saber menos fatalista e mais autônomo acerca da intervenção escolar que pudesse porventura gerar contra-efeitos ou, pelo menos, novas apropriações desse já conhecido estado de coisas?

Talvez, uma alternativa viável seja mesmo de ordem conceitual, responsável pela delimitação do raio de nosso olhar, como a que se proporá a partir de agora.

\section{Um olhar institucional sobre a violência escolar}

A fim de aprofundar a discussão, vale a pena enunciar, de imediato, o conceito de instituição com o qual comungamos. Nas palavras de Guirado (1997, p. 34),

estamos definindo as instituições como relações ou práticas sociais que tendem a se repetir e que, enquanto se repetem, legitimam-se. Existem, sempre, em nome de um "algo" abstrato, o que chamamos de seu objeto. Por exemplo, a medicina pode ser considerada, segundo nossa definição, uma instituição e seu objeto, pode-se dizer, é a saúde. As instituições fazem-se, sempre também, pela ação de seus agentes e de sua clientela. De tal forma que não há vida social fora das instituições e sequer há instituição fora do fazer de seus atores.

$\mathrm{Na}$ definição delineada acima, a autora oferece interessantes pistas para a compreensão das instituições como relações ou práticas sociais específicas. Vejamos por quê. 
É bastante comum pensarmos as práticas sociais, e dentre elas a escola, como donatárias inequívocas do contexto histórico, isto é, da conjuntura política, econômica e cultural. É bem verdade também que nos acostumamos a deduzir que o que se desenrola no interior de tais instituições é uma espécie de efeito-cascata daquilo que se gesta em seu exterior. Mas seria plausível atribuir uma gênese única aos meandros de diferentes práticas institucionais, com seus objetos, atores e práticas singulares?

Convenhamos, é mais do que evidente que as relações escolares não implicam um espelhamento imediato daquelas extra-escolares. Ou seja, não é possível sustentar categoricamente que a escola tão-somente "reproduz" vetores de força exógenos a ela. É certo, pois, que algo de novo se produz nos interstícios do cotidiano escolar, por meio da (re)apropriação de tais vetores de força por parte de seus atores constitutivos e seus procedimentos instituídos/instituintes.

Em suma, vale afirmar que é mais um entrelaçamento, uma interpenetração de âmbitos, entre as diferentes instituições que define a malha de relações sociais do que uma suposta matriz social e suprainstitucional, que a todos submeteria. Afinal, não é possível admitir que o cotidiano das diferentes instituições opera, por completo, à revelia dos desígnios de seus atores constitutivos, nem que sua ação se dá, de fato, a reboque de determinações macroestruturais abstratas. Nesse sentido, a equivalência entre ação institucional escolar e reprodução macroestrutural deixa de fazer sentido como uma verdade em si mesma - verdade esta que geralmente se expressa na idéia de "a" instituição como uma entidade alheia, poderosa e involuntária, em confronto com a prática concreta de seus agentes e clientela.

Cabe-nos pontuar que não estamos desacompanhados nesse tipo de posicionamento descentralizador na análise dos fenômenos escolares. Guimarães (1996b) defende uma compreensão da díade violência/indisciplina escolar bastante congruente com a nossa. Vejamos. "A instituição escolar não pode ser vista apenas como reprodutora das experiências de opressão, de violência, de conflitos, advindas do plano macroestrutural. É importante argumentar que, apesar dos mecanismos de reprodução social e cultural, as escolas também produzem sua própria violência e sua própria indisciplina" (p. 77).

Já quanto à perspectiva psicologizante adotada como alternativa na leitura de determinados eventos escolares, também não é possível situarmos a gênese de determinada problemática institucional concreta 
em torno de um núcleo conceitual abstrato como o de "personalidade" ou mesmo de "identidade", ou ainda de "perfil" atrelado a um padrão de desenvolvimento -, independentemente da configuração institucional na qual o sujeito da ação está inserido.

Portanto, idéias como "desestruturação da personalidade" ou "déficit em alguma fase de desenvolvimento" também deixam de fazer sentido em si mesmas quando se colocam em foco questões de ordem institucional. O sujeito concreto, enquadrado em determinadas coordenadas institucionais específicas, não pode ser encarado como um protótipo individual de uma suposta "natureza humana padrão", tomada como modelo universal, ideal e compulsório, que não comportaria idiossincrasias (tomadas, por sua vez, como desvio, anomalia, distúrbio).

Outrossim, o sujeito só pode ser pensado na medida em que pode ser situado num complexo de lugares e relações pontuais - sempre institucionalizadas portanto. A noção de sujeito passa a implicar, dessa forma, a premissa de lugar institucional, a partir do qual ele pode ser regionalizado no mundo; sujeito (sempre) institucional, portanto. Ele é estudante de determinada escola, aluno de certo(s) professor(es), filho de uma família específica, integrante de uma classe social, cidadão de um país, e assim por diante.

Sujeito que só o é concretamente como efeito de uma equação institucional que requer obrigatoriamente um outro complementar, portanto, uma relação pontual. $E$, sendo assim, que ocupa um lugar determinado em relação a esse outro, portanto, parceiro de uma relação institucionalizada, e que o faz sempre de modo singular. Ou seja, está inserido em uma relação, ocupa um lugar determinado nessa relação, e dele se apodera de acordo com uma maneira específica, isto é, posiciona-se em relação a ele.

Nessa linha de raciocínio, propor um olhar especificamente institucional sobre práticas institucionais, em detrimento da primazia de outros olhares já consagrados, demanda algumas decisões teóricometodológicas, dentre as quais:

- abandonar o projeto de uma leitura totalizadora (quer de ordem sociologizante, quer de ordem psicologizante) dos fenômenos em foco, matizando-os de acordo com sua configuração institucional. Por exemplo, não se pode conceber a questão da violência no contexto escolar como se estivéssemos analisando a violência na 
família, nas prisões, nas ruas, e como se todas elas fossem sintomas periféricos de um mesmo "centro" irradiador;

- regionalizar o epicentro do fenômeno, situando-o no intervalo das relações institucionais que o constituem. No caso da escola, a tarefa passa a ser rastrear, no próprio cenário escolar, as cenas constitutivas assim como as nuanças dos efeitos de violência que lá são testemunhados;

- descrever e analisar as marcas do fenômeno tomando como dispositivo básico as relações institucionais que o retroalimentam. No caso escolar, situar o foco de análise nas relações dominantes no contexto escolar, em particular na relação professor-aluno.

\section{Violência e autoridade no espaço escolar}

Considerados alguns contornos conceituais do debate violência/ escola, assim como as implicações teórico-metodológicas de uma leitura institucional do tema, nosso próximo passo requer a imersão na temática pelo ângulo em pauta. Para tanto, partamos do pressuposto de que um dos vetores que transversalizam a dinâmica escolar (em particular a ação do professor, na qualidade de agente privilegiado) é o teor normativo/confrontativo que esta invariavelmente assume. E, novamente, Guimarães (1996b, pp. 78-79) oferece-nos pistas adicionais para a compreensão dessa dinâmica confrontativa.

A escola, como qualquer outra instituição, está planificada para que as pessoas sejam todas iguais. Há quem afirme: quanto mais igual, mais fácil de dirigir. A homogeneização é exercida através de mecanismos disciplinares, ou seja, de atividades que esquadrinham o tempo, o espaço, o movimento, gestos e atitudes dos alunos, dos professores, dos diretores, impondo aos seus corpos uma atitude de submissão e docilidade. Assim como a escola tem esse poder de dominação que não tolera as diferenças, ela também é recortada por formas de resistência que não se submetem às imposições das normas do dever-ser. Compreender essa situação implica aceitar a escola como um lugar que se expressa numa extrema tensão entre forças antagônicas. (...) O professor imagina que a garantia do seu lugar se dá pela manutenção da ordem, mas 
a diversidade dos elementos que compõem a sala de aula impede a tranqüilidade da permanência nesse lugar. Ao mesmo tempo que a ordem é necessária, o professor desempenha um papel violento e ambíguo, pois se, de um lado, ele tem a função de estabelecer os limites da realidade, das obrigações e das normas, de outro, ele desencadeia novos dispositivos para que o aluno, ao se diferenciar dele, tenha autonomia sobre o seu próprio aprendizado e sobre sua própria vida. (Grifos nossos)

Se partirmos do pressuposto de que a intervenção escolar é estruturalmente normativa/confrontativa (até mesmo para que seus propósitos gerais sejam garantidos), nosso olhar volta-se para a relação professor-aluno como locus, ao mesmo tempo estrutural e conjuntural, da violência escolar.

Aos desavisados, uma advertência teórica e, ao mesmo tempo, ética. Não estamos com isso, em nenhuma hipótese, avalizando a violência escolar; muito menos atribuindo a quaisquer pólos da relação responsabilidades exclusivas. Ao contrário, estamos defendendo uma espécie de mão dupla instituinte: há uma violência "positiva", imanente à intervenção escolar, constitucional e constituinte dos lugares de professor e aluno. Nesse sentido, a relação professor-aluno, em vez de tão-somente "importar" efeitos de violência exógenos a ela, os institui quase compulsoriamente. É a partir dessa natureza conflitiva que se pode derivar, a nosso ver, um certo olhar mais "produtivo" sobre o cotidiano escolar contemporâneo e o que os rastros de violência nele embutidos têm-nos revelado sobre ele.

Permitam-nos, contudo, um recuo, a título de densificação do próprio conceito em foco: o de violência, propriamente. Por violência denota-se a "qualidade do que atua com força ou grande impulso; força, ímpeto, impetuosidade (...) // intensidade (...) // irracibilidade // força que abusivamente se emprega com o direito // opressão, tirania // ação violenta // (jur.) constrangimento exercido sobre alguma pessoa para obrigála a fazer ou a deixar de fazer um ato qualquer; coação" (Caldas Aulete 1964, pp. 4231-4232).

Como se pode notar à primeira vista, o termo não implica exclusivamente uma conotação negativa. Ou melhor, ele comporta uma ambivalência semântica digna de interesse. Algo que pode ser definido como "intensidade" não pode ser tomado como sinônimo imediato 
de algo que se defina por "irracibilidade", embora ambos portem em comum o caráter de "força" ou "impulso". Uma ação desencadeadora de algo novo poderia, portanto e em certa medida, ser conotada como violenta da mesma forma que uma ação que visasse ao oposto, ou seja, à manutenção de um estado qualquer. A transformação ou a conservação de uma situação ou de um estado de coisas, desde que levadas a cabo com força/ímpeto, poderiam ser compreendidas como igualmente violentas. É o que se evidencia na definição última, jurídica, do termo: trata-se de um "constrangimento" que se exerce sobre outrem com o objetivo de "obrigá-lo" tanto a "fazer" como a "deixar de fazer" um ato qualquer.

Com efeito, sempre que nos posicionamos perante um outro na qualidade de representantes hierárquicos de determinada prática social, seja com o intuito que for, estabelecemos uma relação, a rigor, violenta. Nesse sentido, pais e filhos são violentos entre si, da mesma forma que médicos e pacientes, sacerdotes e fiéis, personagens televisivos e espectadores, professores e alunos. É o que se poderia conceber, grosso modo, como uma espécie de "liturgia" dos lugares e, por extensão, das relações institucionais.

Se toda intervenção institucional vislumbra, inequivocamente, a apropriação de determinado objeto (a saúde na medicina, a salvação nas religiões, o lazer/informação na mídia, o conhecimento na educação escolar etc.), por meio da transformação de uma determinada matéria-prima materializada nas condições apriorísticas da clientela (a descrença, a doença, a ignorância etc.), é possível e desejável, portanto, deduzir que a ação dos agentes institucionais será inevitavelmente violenta porque transformadora.

E como isso se processará? Dentre outros dispositivos, por meio da imagem de "autoridade" atribuída aos agentes, isto é, por meio dos poderes que a clientela (mais imediatamente) e o público (menos imediatamente, uma vez que não participa diretamente da ação institucional) delegarão à figura dos agentes institucionais e, por conseqüência, à potência embutida nessa delegação. É nessa espécie de "promessa" depositada no agente, por parte da clientela/público, que residirá grande parte da eficácia operacional - leia-se imaginária - das instituições. Sem ela, não haveria a possibilidade de existência concreta para as práticas institucionais que tomamos como naturalizadas, imprescindíveis ou mesmo inevitáveis.

Voltemos às definições; desta vez, do conceito de autoridade. 
Os significados do termo autoridade remetem a "direito, poder de comandar, de obrigar a fazer alguma coisa; domínio, jurisdição // arbítrio, vontade própria (...) // aquele que exerce autoridade (...) // crédito, consideração, influência, importância (...) // autorização, permissão" (ibid., p. 341).

Como se pode subtrair de chofre, o sentido basal do termo desdobra-se em torno da idéia de exercício outorgado de poder, portanto, um exercício de direito. Mais especificamente, trata-se da delimitação de uma jurisdição/domínio - institucional, evidentemente - ou até mesmo de uma espécie de arbitragem ou comando, concedida a partir da autorização/permissão de outrem, que se efetiva de acordo com o crédito (ou consideração/influência/importância) atribuído àquele; portanto, um exercício de direito legitimado.

Nesse sentido, corroboramos a premissa de que a potência virtual da ação institucional dá-se via delegação de "poderes" aos agentes, pela clientela/público, avalizada pela crença numa certa "superioridade" hierárquica (leia-se, "saberes") daqueles - porque mais próximos do objeto institucional, quer pela sua posse quer pela sua guarda. $\mathrm{E}$, finalmente, na definição do termo autoridade, desponta uma evidente justaposição semântica a um dos sentidos do termo violência: o de "obrigar a fazer alguma coisa".

Grosso modo, poder-se-ia concluir que, de um ponto de vista institucional, não há exercício de autoridade sem o emprego de violência, e, em certa medida, não há o emprego de violência sem exercício de autoridade. Portanto e em suma, a violência como vetor constituinte das práticas institucionais teria como um de seus dispositivos nucleares a própria noção de autoridade, outorgada aos agentes pela clientela/público, e avalizada pelos supostos "saberes" daqueles". Por essa razão, reafirmamos a convicção de que há, no contexto escolar, um quantum de violência "produtiva" embutido na relação professor-aluno, condição sine qua non para o funcionamento e a efetivação da instituição escolar.

\section{A crise da autoridade docente: Alguns nortes éticos}

Se partirmos do pressuposto de que, nas sociedades complexas, a educação escolar é o modo dominante por meio do qual as novas gerações são inseridas na tradição, isto é, o meio pelo qual as introduzimos no instável (e sempre inusitado) mundo do conhecimento sistema- 
tizado, haveremos de convir que alguns fantasmas têm rondado essa instituição secular. E o mais implacável deles talvez seja o que envolve a crise da autoridade docente - fato este que, a nosso ver, seria o correlato principal de grande parte dos efeitos de violência testemunhados no cenário escolar.

Afirmamos anteriormente que a autoridade delegada aos agentes de determinada instituição é um dos dispositivos basais de estruturação e efetivação da própria intervenção institucional. $E$, nesse sentido, se a escola contemporânea tem-se apresentado cada vez mais como um espaço de confrontos que em muito ultrapassam aqueles relativos ao embate intelectual/cultural, é possível supor, então, que seu âmbito (ou o escopo específico de sua ação) padeça de uma certa ambigüidade, ou ineficácia, por parte daqueles que a fazem cotidianamente. Trata-se, sem dúvida, de uma crise, ao mesmo tempo, paradigmática e ética.

A crise da autoridade na educação guarda a mais estreita conexão com a crise da tradição, ou seja, com a crise de nossa atitude perante o âmbito do passado. É sobremodo difícil para o educador arcar com esse aspecto da crise moderna, pois é de seu ofício servir como mediador entre o velho e o novo, de tal modo que sua própria profissão Ihe exige um respeito extraordinário pelo passado. (Arendt 1992, pp. 243-244)

Hannah Arendt, no magnífico texto intitulado $A$ crise na educação, oferta aquilo que, a nosso ver, constitui a única estratégia fecunda de enfrentamento dessa crise ético-paradigmática que assola a educação escolar contemporânea: o respeito pelo passado, pela tradição corporificada no legado cultural.

Desta feita, escola é, por excelência, lugar do passado, no bom e imprescindível sentido do termo. E deve ser. Mesmo porque não há futuro plausível sem a imersão no traçado histórico dos diferentes campos de conhecimento (leia-se, as ciências, as artes, as humanidades, os esportes). E isso, por mais que alguns se ressintam do termo, é denominado "tradição". E vale frisar: tradição não é sinônimo de anacronismo, assim como autoridade não é sinônimo de despotismo. Muito ao contrário.

É aí também que o trabalho escolar revela outro de seus paradoxos de base: é preciso conservar (o patrimônio cultural) para transformar 
(as novas gerações, os "forasteiros"). Sendo assim, no mesmo golpe recria-se a cultura e inventa-se o sujeito da cultura. E esse princípio fundamental, caríssimo a todo aquele envolvido ciosamente com o trabalho escolar, implica, por sua vez,

uma compreensão bem clara de que a função da escola é ensinar às crianças como o mundo é, e não instruí-las na arte de viver. Dado que o mundo é velho, sempre mais que elas mesmas, a aprendizagem volta-se inevitavelmente para o passado, não importa o quanto a vida seja transcorrida no presente. (Ibid., p. 246)

A essa espécie de visibilidade sobre os princípios e fins da ação docente temos denominado "ética pedagógica", ${ }^{2}$ uma vez que ela não implica imediatamente nem a dimensão teórica da ação (os conteúdos em foco) nem sua dimensão metodológica (os procedimentos em jogo). Antes, ela os perpassa, Ihes é imanente e fundante. Assim, a questão da autoridade, para além da qualificação stricto sensu do professor, passa a se configurar como o ponto nevrálgico da ética docente, reguladora primordial do trabalho pedagógico, e, portanto, como o único antídoto possível contra a violência escolar.

Novamente, Arendt aponta caminhos importantes:

Embora certa qualificação seja indispensável para a autoridade, a qualificação, por maior que seja, nunca engendra por si só autoridade. A qualificação do professor consiste em conhecer o mundo e ser capaz de instruir os outros acerca deste, porém, sua autoridade se assenta na responsabilidade que ele assume por este mundo. Em face da criança, é como se ele fosse um representante de todos os habitantes adultos, apontando os detalhes e dizendo à criança: - Isso é o nosso mundo. (Ibid., p. 239)

A título de encerramento, valeria indagar, tomando como contraponto concreto a violência nossa de cada dia, da qual nos pensamos reféns a maior parte do tempo: Qual mundo temos apresentado a nossos alunos? Quais de seus detalhes Ihes temos apontado? Qual história queremos legar para as novas gerações? Há ainda, no encontro habitual da sala de aula, responsabilidade por este mundo e esperança de um outro melhor? 


\section{Notas}

1. Em certo sentido, essa compreensão "positiva" da díade violência/autoridade, como instituinte das relações institucionais, assemelha-se à proposição foucaultiana sobre o poder. "Temos que deixar de descrever sempre os efeitos de poder em termos negativos: ele 'exclui', 'reprime', 'recalca', 'censura', 'abstrai', 'mascara', 'esconde'. Na verdade o poder produz; ele produz realidade; produz campos de objetos e rituais da verdade. O indivíduo e o conhecimento que dele se pode ter originam-se nessa produção" (Foucault 1987, p.172).

2. Para maiores esclarecimentos, consultar o texto de nossa autoria intitulado "Ética na escola: A diferença que faz diferença", incluído no livro Diferenças e preconceito na escola: Alternativas teóricas e práticas, referenciado na bibliografia.

\section{School violence and the crisis of teacher authority}

ABSTRACT: The present article intends to discuss the relationship between the concepts of violence and authority within school context nowadays and, mainly, within teacher-student relationship. For that purpose, it proposes an institutional approach of school violence opposed to the classical approaches of the subject in focus, demonstrating the thesis according to which there is an amount of "productive" violence enclosed in the pedagogical action.

\section{Bibliografia}

AQUINO, J.G. Confrontos na sala de aula: Uma leitura institucional da relação professor-aluno. São Paulo: Summus, 1996a.

. "A desordem na relação professor-aluno: Indisciplina, moralidade e conhecimento". In: (org.). Indisciplina na escola: A/ternativas teóricas e práticas. São Paulo: Summus, 1996b, pp. 39-55.

. "Ética na escola: A diferença que faz diferença". In:

(org.). Diferenças e preconceito na escola: Alternativas teóricas e práticas. São Paulo: Summus, 1998, pp. 135-151.

ARENDT, H. Entre o passado e o futuro. $3^{\underline{a}}$ ed. São Paulo: Perspectiva, 1992. 
CALDAS AULETE. Dicionário contemporâneo da língua portuguesa. $3^{\mathrm{a}}$ ed. Rio de Janeiro: Ed. Delta, 1964.

GUIMARÃES, A.M. A dinâmica da violência escolar: Conflito e ambigüidade. Campinas: Autores Associados, 1996a.

. "Indisciplina e violência: ambigüidade dos conflitos na escola". In: AQUINO, J.G. (org.). Indisciplina na escola: Alternativas teóricas e práticas. São Paulo: Summus, 1996b, pp. 73-82.

GUIRADO, M. Psicologia institucional. São Paulo: EPU, 1987.

- Psicanálise e análise do discurso: Matrizes institucionais do sujeito psíquico. São Paulo: Summus, 1995.

. "Sexualidade, isto é, intimidade: Redefinindo limites e alcances para a escola". In: AQUINO, J.G. (org.). Sexualidade na escola: Alternativas teóricas e práticas. São Paulo: Summus, 1997, pp. 25-42. 